\title{
Statistical Approach for Modeling of Daily Global Solar Radiation on Horizontal Surfaces Over Hebron City, Palestine
}

\author{
Husain Alsamamra*
}

Al-Quds University, Department of Physics, Jerusalem, P O Box 20002, Abu-Dies, Palestine

\begin{abstract}
Understanding solar radiation data is essential for modeling solar energy systems because it is non-polluting, non-depletable, reliable, and pollution free. Four-years measured average daily global solar radiation data on horizontal surfaces at Hebron city in Palestine were used for the model assessment. Statistical results showed that all four suggested models can accurately predict the solar irradiance of a $31^{\circ} 57^{\prime} \mathrm{N}$ (latitude angle of Hebron) on a horizontal oriented surface, indicating the good predictive ability for modeling a horizontal surface. The obtained models have a high value of regression coefficient and give best fit through the measured values. This work illustrates also the use of mathematical formula to develop a predictive model for the duration of sunshine using measured solar radiation data for Hebron city. The present work showed that the predicted results were in good agreement with the observed data, and the expected solar radiation behavior.
\end{abstract}

Keywords: Global Solar Radiation, Correlation Formulas, Sunshine duration.

\section{INTRODUCTION}

Just as the fossil fuel based energy industry relies on exploration and proven reserves for discovery and economic support of energy markets, the renewable energy sector depends upon the assessment of resources for planning and selling their energy production technology. For solar-based renewable energy technologies such as solar thermal or photovoltaic conversion systems, the basic resource or fuel available is solar radiation [1-2]. Solar energy can be considered as the most abundant continuing source of energy available to the human species. While solar energy is not being used as a primary source of fuel energy at the present time, a large research and development effort is underway to develop economical systems to harness solar energy and make it a major source of fuel energy [3-4]. A prerequisite to the design of solar collector systems is the availability of solar irradiance data at the required location. It would be cost effective for solar collector system when the utility load and solar resource profiles are well matched. Due to high and reliable solar irradiance of about $5.4 \mathrm{kWh} / \mathrm{m}^{2}$ day a domestic usage for solar energy in Palestine over the life time has the potential to produce a domestic hot water for about 330 sunny days per year using solar collectors [5]. Solar irradiance varies with season and time of the day due to the various Sun positions under the unpredictable weather conditions [6-8]. Systematic long-term data measurements are regarded as the most effective and accurate method of setting up the solar irradiance database. In many parts of the world, however, the basic solar irradiance data

*Address correspondence to this author at the Al-Quds University, Department of Physics, Jerusalem, P O Box 20002, Abu-Dies, Palestine;

E-mail: samamra@science.alquds.edu for the surfaces of interest are not always readily obtainable. Conventionally, different mathematical models have been developed in the literature to predict the solar irradiance on various inclined-surfaces using horizontal data [9-11]. For places where measured data are not obtainable, generating the required solar radiance data from conversion solar-radiance models would also be an appropriate solution [12-13]. Most solar radiation data available are for horizontal surfaces; include both direct and diffuse radiation. The most common measurements of solar radiation are total radiation on a horizontal surface, often referred to as global radiation on the surface. Data on average hours of sunshine or average percentage of possible sunshine hours are widely available from stations in many countries [14]. The potential solar radiation is computed based on latitude, slope, aspect, topographic shading and time during the year [15]. It is corrected for monthly sunshine hours and cloudiness factors. Solar radiation measurements provide data with huge spatial dispersion. Many sophisticated models for computing solar radiation, that take in the consideration more of the astronomical, meteorological and surface influences, have been developed [16]. In this paper, studies on the prediction of global daily solar radiation on horizontal surfaces have been carried out and predicted formulas were used to model solar radiation in Hebron. Also, the monthly average of sunshine duration for Hebron city has been predicted. A comparative assessment of the irradiance and sky distribution models is reported and the characteristics of the findings are discussed.

\section{EXISTING KNOWLEDGE AND AIM OF PRESENT WORK}

Palestinian people import all of its needs of petroleum from the Israeli market and also about $92 \%$ 
of electrical energy from the Israeli Electrical Corporation. The production of renewable energy contributes only $1.9 \%$ of the total energy during the year 2009 [17]. In fact, Palestine is blessed with huge amounts of renewable energy resources, particularly solar and wind energies [18]. The duration of solar radiation and its energy that reaches the ground are becoming important spatial data. Solar radiation research is significant not only for meteorologists but also for foresters, agronomists, geographers and others. Solar energy, on the other hand, is almost unlimited and it is considered to be the energy of the future. Solar radiation modeling has been used in agricultural and forested areas [15, 19-20]. Incoming solar radiation, through its influence on the energy and water balance at the earth's surface, affects such processes as air and soil heating, evapotranspiration, photosynthesis, winds, and snow melt [21-23]. In contrast to the high cost of building and maintaining insolation monitoring stations, spatially based solar radiation models provide a cost-efficient means for characterizing the spatial and temporal variation of insolation. The solar flux model [24-26] simulates the influence of shadow patterns on direct insolation at discrete intervals through time. The prediction formulas are powerful tools that can be used to model and investigate various highly complex and nonlinear phenomena. Solar Radiation readings are usually very difficult if not impossible to correlate. If algebraic correlations are developed in the standard manner the results are usually accompanied by a high degree of uncertainty. During the last few years, the solar radiation data has only been presented in tabular or graphical form. Application of such data for design calculations can be very difficult. Many parameters influence the amount of solar energy at a particular standing point of the Earth's surface; therefore, many solar radiation models were produced in the last few years [27-28]. By using horizontal data, different mathematical models can be developed to predict the solar irradiance on various inclined surfaces. In the present paper, a correlation formula, which is more practical and efficient than the tabulated data, has been suggested to predict the incident daily global solar radiation on horizontal surfaces in Hebron city at Palestine.

\section{THEORETICAL BACKGROUND}

Global solar radiation is an important climate variable with respect to many fields as agriculture or renewable energy applications. The energy of global radiation is influenced by incidence angle of the Sun's position, geomorphology of the Earth surface, and climate. The direct solar insolation on a surface normal to the sun's rays depends on the time of day, the time of year, and the local latitude as well as the amount of cloud cover [29-31]. It has been pointed out that sky's diffuse-component is considered to be the largest potential source of computational error [16, 32]. When the whole sky is being considered, multiple scattering effects from the atmospheric factors such as aerosols, ozone and nitrogen-dioxide content on the sky diffuse component would be complicated and difficult to evaluate [33]. Solar radiation is the major energy source on earth and solar energy can play an important role in meeting the ultimate goal of replacing fossil fuels. Currently, a local study on renewable energy reported that solar technologies are potentially suitable for wide scale applications in Palestinian territories [5]. These results show that Palestine need to begin to rely more on solar energy in order to reduce the dependence on imported expensive sources of energy. Therefore, we recommend that the Palestinian authority activities on solar energy should be increased to get benefits from the large number of sunny days during the year and the large value of global solar radiation as was shown in the results. In general, Palestine has a high solar energy potential, where average solar energy is between $2.63 \mathrm{kWh} / \mathrm{m}^{2}$ day in December to $8.4 \mathrm{kWh} / \mathrm{m}^{2}$ day in June, and the daily average of solar radiation intensity on horizontal surface is $5.4 \mathrm{kWh} / \mathrm{m}^{2}$ day [18]. One of the applications for the prediction models is to calculate the solar irradiance on horizontal surfaces for solar collector system designs. As Hebron is located at latitude of $31^{\circ} 57^{\prime} \mathrm{N}$, it would be useful to determine the solarirradiance data on a horizontal surface with a tilt angle of $31^{\circ} 57^{\prime}$ facing south. The calculation of global radiation energy was numerically simplified. Hourly values were calculated for the mean day. Daily values were obtained as a sum of hourly energies. The annual global radiation energy was calculated with the sum of energy over four years. All the calculations were preformed in Fortran and Matlab, which is optimized for working with matrices and it is relatively easy to program.

\subsection{Regression Coefficient and Statistical Equations}

After choosing the best correlation formula that gives a good fitting through most reading, the regression coefficient has been calculated to check the prediction formula. The regression coefficient is one of the most important indications about the correlation 
formula. If its value close to one, this means that the regression formula is fitting through most of measurement data. The regression coefficient can be defined as [34]:

$$
R=\sqrt{\frac{\sum_{i=1}^{n}\left(G_{i}-\bar{Y}\right)^{2}}{\sum_{i=1}^{n}\left(Y_{i}-\bar{Y}\right)^{2}}}
$$

\section{Where}

$Y_{i}$ is the measured value $\left(\mathrm{Wh} / \mathrm{m}^{2}\right.$ day $)$,

$G_{i}$ is the calculated or predicted value from the obtained formula $\left(\mathrm{Wh} / \mathrm{m}^{2}\right.$ day), and is the average value $\left(\mathrm{Wh} / \mathrm{m}^{2}\right.$ day $)$, which can be defined as:

$\bar{Y}=\frac{\sum_{i=1}^{n} Y_{i}}{N}$

The standard error, $S$, is an indication of variation between the measured and predicted values because the variance involves a sum of squares error. The standard deviation can be defined as:

$$
S=\sqrt{\frac{\sum_{i=1}^{n}\left(Y_{i}-G_{i}\right)^{2}}{N-M R}}
$$

where $N$ is the number of fitted points and $M R$ is the number of Regression coefficient. The residual can be defined as the difference between the measured and the predicted value as shown in the following equation:

$$
\text { Residual }=Y_{i}-G_{i}
$$

The relative error is the difference between the measured and predicted values (residual) divided by the measured value as shown by the following equations:

$$
\text { Residual error }=\frac{Y_{i}-G_{i}}{Y_{i}}
$$

The level of confidence associated with intervals of measurements data is typically taken as 0.95 . In the present results for every prediction formula, the values form the prediction formulas were calculated and the errors were estimated, then the percentage of error was calculated. Also, 95\% prediction interval was calculated and $95 \%$ confidence interval was also calculated.

\section{RESULTS AND DISCUSSIONS}

The global solar radiation and sunshine duration data employed in this work were supplied by the
Palestinian meteorological office. A radiometric station was established at the Hebron city (1000 m above sea level). During the (48-month) period from January (2007) to December (2010), data for other periods were checked but unfortunately there were big gaps encountered. Measurements including horizontal solar irradiance and sunshine duration were made on the rooftop in a position relatively free from any external obstructions. Data collection started before sunrise and finished after sunset. All measurements were referred to true solar-time. This facilitates the computations involving solar altitude for the extraterrestrial irradiance on unit horizontal surface and the subsequent comparison of data for different locations. The predicted solar irradiance values were compared with the measured results. The comparison was conducted on an hourly basis. Figure 1 shows the global solar radiation data on a horizontal surface for Hebron city. Some scatters in the data can be shown in Figure 1 since the average value of the global solar daily radiation in Hebron has been taken for four years, therefore the number of years used to calculate the average global solar daily radiation is small and if the weather is a cloudy in a summer day, the global solar radiation value would be largely affected.

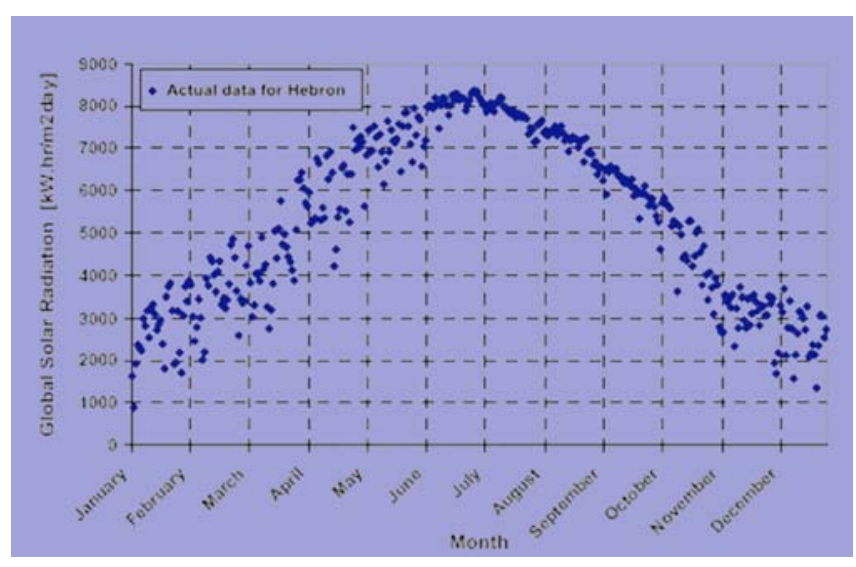

Figure 1: Global daily solar radiation data for Hebron, Palestine.

Meteorological data were acquired from observed mean values on meteorological stations between 2007 and 2010. All measurements were made for hours and decades and finally, the annual global radiation energy, which is the energy received by horizontal plane from the Sun in one year, was calculated from the sum of all the energies of all the decades. Reliable solar radiance distribution databases should be based on long-term systematic measurements. For places where solar radiance distributions are not available, an appropriate model for solar radiation and sunshine duration can be used to generate the required data. 


\subsection{Correlation Formula}

Radiation data are the best source of information for estimating the average incident radiation. Lacking of these data from nearby locations of similar climate, it's possible to use empirical relationships to estimate radiation on a horizontal surface as a function of time. Four correlation formulas with high regression coefficients have been obtained for predicting the global daily solar radiation data for Hebron city. The general form for these models and the values of their constants are briefly discussed below. Observed global solar radiation data were used to evaluate the accuracy of each model.

\section{Sine wave Correlation Formula with Constant Y- Value}

The general formula for the sine wave correlation formula with constant $\mathrm{Y}$-value can be represented as:

$G=a_{2}+a_{0} \sin \left(\frac{2 \pi x}{a_{2}}+a_{1}\right)$

where $a_{0}$ is the amplitude, $a_{1}$ is the phase shift, $a_{2}$ is the wave length and $a_{3}$ is the $y$ intercept. By substituting the suitable values for these constants in equation (6), then the correlation formula for global solar radiation for Hebron city can be written as:

$G=5256.65+2782.09 \sin \left(\frac{2 \pi x}{375.43}+4.783\right)$

The Regression coefficient, $R$, for the data in equation (7) is 0.964 which indicates that the model predicts well the global solar radiation data. The standard error $=0.536 \mathrm{kWh} /\left(\mathrm{m}^{2}\right.$ day $)$ which is also acceptable and within the range.

\section{Lorentzin Correlation Formula}

The general formula for the Lorentzin correlation formula can be represented as:

$$
G=\frac{a_{0}}{1+\left(\frac{x-a_{1}}{a_{2}}\right)^{2}}
$$

where $a_{0}$ is the amplitude, $a_{1}$ is the center and $a_{2}$ is the width. After substituting the values for these constants in equation (8), then the correlation formula for global solar radiation for Hebron city can be written as:

$$
G=\frac{8220}{1+\left(\frac{x-183.4}{119.8}\right)}
$$

The Regression coefficient, $R$, for the data in equation (9) is 0.961 which is also a very good value and the standard error $=0.556 \mathrm{kWh} /(\mathrm{m} 2 \mathrm{day})$ which is also acceptable.

\section{Gaussian Correlation Formula}

$G=a_{0} \exp \left[-0.5 *\left(\frac{x-a_{1}}{a_{2}}\right)^{2}\right]$

where $a_{0}$ is the amplitude, $a_{1}$ is the center and $a 2$ is the width. By substituting the values for these constants in equation (10), then the correlation formula for global solar radiation for Hebron city can be written as:

$G=7905.65 \exp \left[-0.5 *\left(\frac{x-183.21}{107.26}\right)^{2}\right]$

The Regression coefficient, $R$, for the data in equation (11) is 0.960 and the standard error is 0.562 $\mathrm{kWh} /\left(\mathrm{m}^{2}\right.$ day $)$.

\section{$4^{\text {th }}$ Order Polynomial Degree Correlation Formula}

$G=a_{0}+a_{1} x+a_{2} x_{2}+a_{3} x_{3}+a_{4} x_{4}$

where $a_{0}, a_{1}, a_{2}, a_{3}$ and $a_{4}$ are the polynomial constants. By substituting the values for these constants in equation (12), then the correlation formula for global solar radiation for Hebron city can be written as:

$G=2706.825-15.5442 x+0.8357 x^{2}-0.0043 x^{3}+0.0002 x^{4}$

The Regression coefficient, $R$, for the data in equation (13) is 0.964 and the standard error is 0.538 $\mathrm{kWh} /(\mathrm{m} 2$ day) which is also acceptable and within the range.

Figure 2 shows the above four suggested correlation formulas plotted together with the measurements of global daily solar radiation for Hebron city as a function of time. A nonlinear trend between predicted and measured irradiance data is evident for each model. Most of the estimated data are in a very good agreement with the corresponding observed data. To examine closely the behavior of the models, an analysis was carried out under overcast and nonovercast conditions

In interpreting sky conditions, climatic parameters should initially be used as weighting factors to indicate the degree of sky clearness so that the sky patterns 


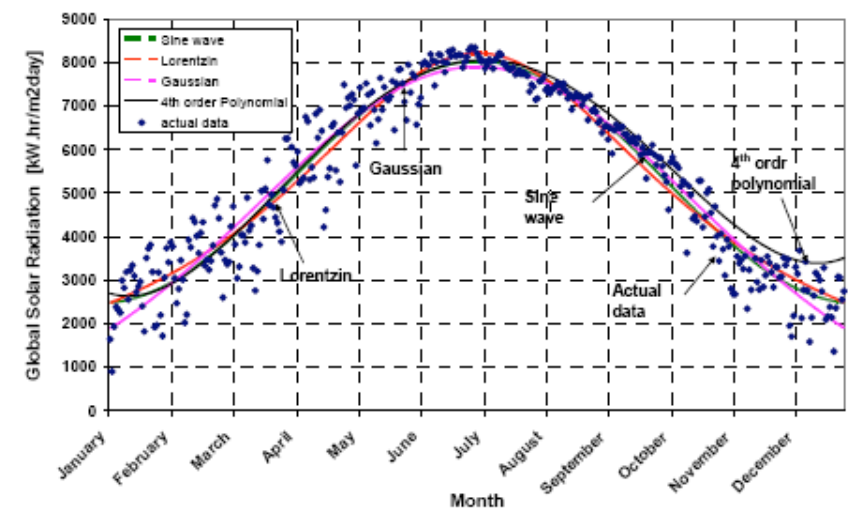

Figure 2: Global daily solar radiation data with different suggested prediction models in Hebron, Palestine as a function of time (day).

can be categorized. The solar radiation at normal incidence received at the surface of the earth is subjected to variations due to change in the extraterrestrial radiation in addition to the two significant phenomena which are the atmospheric scattering by air molecules, water and dust and the atmospheric absorption. Astronomical data has the lowest effect on the value of global radiation energy. They are followed by meteorological and surface data, which have the highest influence. Furthermore, the application quality is almost unaffected by astronomical and surface data. Poor meteorological data have the highest influence on the application quality. Therefore, better surface and astronomical data would not make a big difference in the final quality, if we did not use meteorological data of higher quality as well. The quality of our application is completely satisfactory.

The changing of the mean value of the monthly energy of global radiation in Hebron is shown on Figure 3. The data in Figure $\mathbf{3}$ for global monthly solar radiation in Hebron has been calculated by estimating

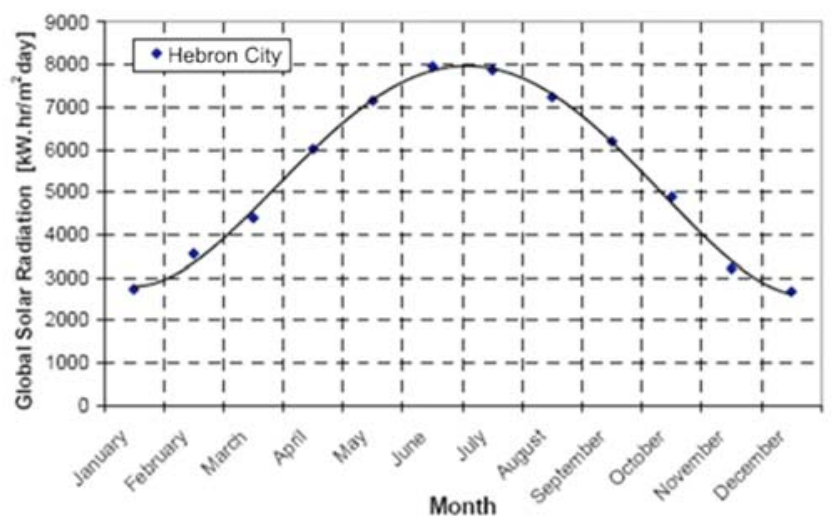

Figure 3: Measured average monthly daily global solar radiation in Hebron, Palestine compared with simulated average monthly daily irradiance at horizontal surface. the average of the daily global solar radiation data for each month.

The resultant global solar radiation integrates over both sunny and cloudy days, and which average the influence of clouds over time. The monthly energy of solar radiation was calculated for each day and then multiplied by 30 days to determine average monthly radiation. Then the $4^{\text {th }}$ order polynomial correlation formula which gives the best fit can be represented by the following equation:

$G=3603.7-1728.1 * M+1059.5 * M^{2}-140.9 * M^{3}+5.3 * M^{4}$

where $M$ is the month number, i.e. January month has a number of 1 and December month has a number of 12.

The result of the study is a dataset of annual energy of global radiation in Hebron. The mean value of energy of global radiation for Hebron equals 5324 $\mathrm{kWh} / \mathrm{m}^{2}$ day. It is also obvious from Figure 3 that Palestine receives the most solar energy in June and July (mean value $7995 \mathrm{kWh} / \mathrm{m}^{2}$ in June and 7875 $\mathrm{kWh} / \mathrm{m}^{2}$ in July) and the least in December (mean value $2676 \mathrm{kWh} / \mathrm{m}^{2}$ ). As expected, the energy of global solar radiation changes the fastest around both equinoxes and the slowest around both solstices.

\subsection{Sunshine Duration}

Sunshine hour ( $\mathrm{SH})$ is a widely-available climatic variable measured at many meteorological stations. The amount of $\mathrm{SH}$ is expressed in fractions of an hour over a 60 min interval. It is logical to take $\mathrm{SH}=0$ for an overcast sky and $\mathrm{SH}>0$ is considered for a nonovercast sky. If a part of the surface is in the shadow, it receives lesser energy than sunny areas. Figure 4 shows the Meteorological data for Sunshine duration in Hebron which acquired from observed mean values on meteorological stations for 4 years. The scattering in the data is very high because the number of years used to calculate the average sunshine duration is only 4 years. At least, measurement for sunshine duration in any region should be taken for 10 years in order to consider these data as the average sunshine duration for this region. The scatter points shown on the figure are due to this small number of years that used to calculate the average value. It is very clear from Figure 4 that it is very difficult to suggest a correlation formula for the sunshine duration from the available measured data which has a high scattering value. One can conclude, considering all the parameter effects, that 
our model provides good results only for long periods over specific areas. As the meteorological part of our model is rather simplified, it is inappropriate for shorter periods. Thus, an improved meteorological model and better meteorological data would make a great improvement of the application results. Furthermore, shadow algorithm could also be taken into account, but changes would only slightly influence the results. Therefore, it is better to use surface data of higher quality. The data shown in Figure $\mathbf{4}$ for daily sunshine duration in Hebron has been averaged for each month and then presented in Figure 5. The monthly average of $\mathrm{SH}$ duration was correlated using a $4^{\text {th }}$ order polynomial formula that can be represented as:

$S H=7.21-3.34 * M+1.56 * M^{2}-0.19 * M^{3}+0.007 * M^{4}$

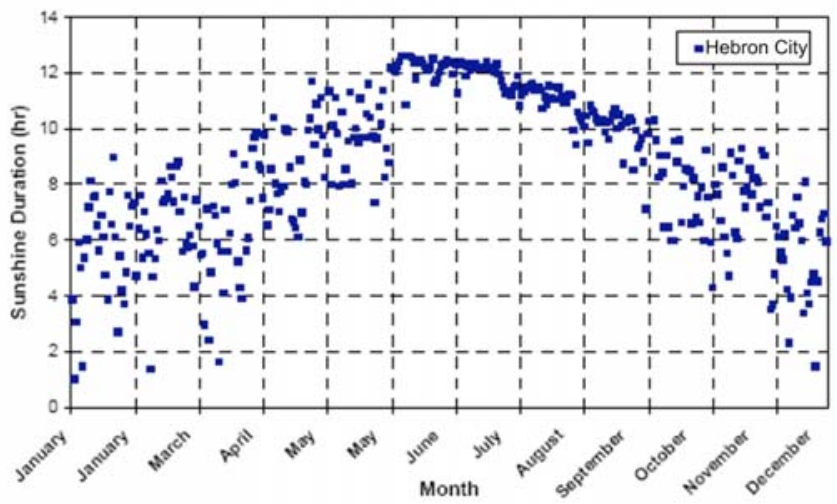

Figure 4: Measured average sunshine duration $(\mathrm{SH})$ data in Hebron, Palestine by days.

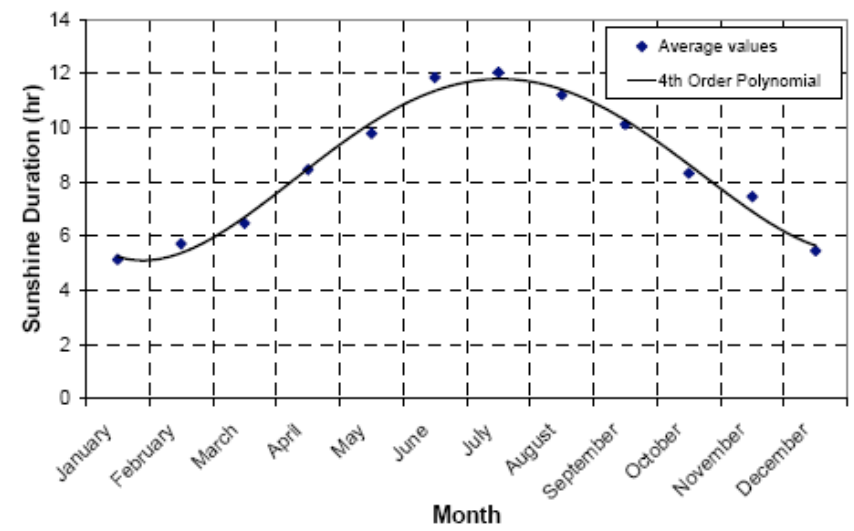

Figure 5: The mean value of the monthly sunshine duration in Hebron, Palestine.

The results of the modeled $\mathrm{SH}$ duration for the location of Hebron compared against measured $\mathrm{SH}$ data show a close agreement between measured and simulated values. Also, It is clear from Figure 5 that the maximum value of $\mathrm{SH}$ duration in Hebron occurs in June and July (mean value is $11.86 \mathrm{~h}$ for June and
$12.05 \mathrm{~h}$ for July) and the least in December (mean value $5.14 \mathrm{~h}$ ).

\section{CONCLUSION}

An evaluation of the predicted solar-irradiance for Hebron horizontal surface using measured data for four years has been conducted in the present work. A highquality global radiation energy model was produced and implemented for Hebron city. The proposed suggested model provided an excellent predictive method for global solar radiation in addition to the monthly averaged value of sunshine duration. The comparison of the predictions with the tabulated values proved that the suggested developed model could be used to successfully model the solar radiation in Hebron area. Accurate solar irradiance models are needed for many applications in agriculture and forestry. It has been found that the sine wave with yshift prediction formula as well as lorentzin formula and $4^{\text {th }}$ order polynomial formulas give excellent fitting and very good regression. At least, the measurement for solar radiation in any region should be taken for 10 years, and then the average value for these data can be considered as the average solar incident radiation for these regions. It was determined that the mean value of solar energy in Hebron city equals 5324 $\mathrm{kWh} / \mathrm{m}^{2}$ day. As expected, Hebron receives the most solar energy in June (mean value $=7995 \mathrm{kWh} / \mathrm{m}^{2}$ day) and July (mean value $=7875 \mathrm{kWh} / \mathrm{m}^{2}$ day) and the least in December (mean value $=2676 \mathrm{kWh} / \mathrm{m}^{2}$ day).

\section{ACKNOWLEDGEMENTS}

We would like to acknowledge the Palestinian meteorological stations network office for their kindly help in providing the data.

\section{REFERENCES}

[1] Mohammed T, Shadi N. Re-evaluation and re-design standalone PV solar lighting projects in Gaza strip, Palestine. The Islamic Univ J 2011; 323: 337-4.

[2] Culp AW. Principles of Energy Conversion, 3rd ed. McGrawHill: New York 1991.

[3] Kurokawa K, Ikki O. The Japanese experiences with national PV-system programs. Sol Energy 2001; 457: 466-3.

[4] Wan W, Nik M, Ibrahim B, Samo A. Monthly mean hourly global solar radiation estimation. Renew Energy 2001; 34333438-3.

[5] Mahmoud M, Ibrik I. Field experience on solar electric power systems and their potential in Palestine. Renew Sustain Energy Rev 2003; 531: 543-7.

[6] Al-Ismaily $\mathrm{H}$, Probert A. Photovoltaic electricity prospects in Oman. Appl Energy 2003; 97: 124-11.

[7] Li D, Lam J. An analysis of climatic variables and design implications", Archit Soc Rev 1999; 15: 25-8. 
[8] Zawilska E, Brooks M. An assessment of the solar resource for Durban. South Africa Renew Energy 2012; 174: 179-3.

[9] Muneer T. Solar radiation model for Europe, Building Services. Eng Res Technoly 1999; 153: 163-5.

[10] Li DH, Lam JC, Lau CS. A new approach for predicting vertical global solar radiance. Renew Energy 2002; 591: 6065.

[11] Li D, Lam J. Predicting solar irradiance on inclined surfaces using sky radiance data. ECM 2004; 1771: 1783-2.

[12] Vartiainen E. A new approach to estimating the diffuse irradiance on inclined surfaces. Renew Energy 2000; 45: 644.

[13] Ruiz-Arias J, Alsamamra H, Tovar-Pescador J, PozoVazquez D. Proposal of a regressive model for the hourly diffuse solar radiation under all sky conditions. ECM 2010; 881: 893-7.

[14] Ambrožič T, cKuhar M, Stopar B, Turk G. Approximation of local geoid surface by artificial neural network. In: Proceedings of Geodesy and Surveying in the Future, Ga"vle, Sweden 1999; pp. 273-6.

[15] Alsamamra $H$, Ruiz-Arias J, Pozo-Vazquez D, TovarPescador J. A comparative study of ordinary and residual kriging techniques for mapping solar radiation over southern Spain. Agric Forest Meteorol 2009; 1343: 1357-3.

[16] Ruiz-Arias J, Pozo-Vazquez D, Santos-Alamillos F, LaraFanego V, Tovar-Pescador J. A topographic geostatistical approach for mapping monthly mean values of daily global solar radiation: A case study in southern Spain. Agric Forest Meteorol 2011; 1812: 1822-4.

[17] Kittaneh $\mathrm{R}$, Alsamamra $\mathrm{H}$, Aljunaidi A. Modeling of wind energy in some areas of Palestine. ECM 2012; 64: 69-5.

[18] Mahmoud M, Ibrik I. Techno-economic feasibility of energy supply of remote villages in Palestine by PV-systems, diesel generators and electric grid. Renew Sustain Energy Rev 2006; 128: 138-2.

[19] Hunt L, Kuchar L, Swanton C. Estimation of solar radiation for use in crop modeling. Agric Forest Meteorol 1998; 293: 300-4

[20] McKenney D, Mackey B, Zavitz B. Calibration and sensitivity analysis of a spatially distributed solar radiation model. Int $\mathrm{J}$ Geog Inf Sci 1998; 49: 65-6.
[21] Swift L. Algorithm for solar radiation on mountain slopes. Water R Res 1976; 108: 112-3.

[22] Dubayah $R$, Rich $P$. Topographic solar radiation models for GIS. Int J Geog Inf Sys 1995; 405: 413-6.

[23] Rich P, Hetrick W, Saving S. Modeling topographic influences on solar radiation: a manual for the SOLARFLUX model. Los Alamos National Laboratory Report LA-12989-M 1995; pp.145-4.

[24] Hetrick WA, Rich PM, Barnes FJ, Weiss SB. GIS-based solar radiation flux models. GIS Photogrammetry Modeling 1993; 132: 143-7.

[25] Rich P, Fu P. Enlightenment for mapping systems: solar radiation models look to the sun for answers. Res Magazine 2000; 7: 8.

[26] Kumar L, Skidmore A, Knowles E. Modeling topographic variation in solar radiation in a GIS environment. Int J Geog Inf Sci 1997; 475: 497-11.

[27] Rehman S, Ghori S. Spatial estimation of solar radiation using geostatistics. Renew Energy 2000; 583: 605-3.

[28] Hocaoğlu F. Stochastic approach for daily solar radiation modeling. Sol Energy 2011; 278: 287-5.

[29] labal M. An Introduction to Solar Radiation. Academic Press: Toronto 1993; p.110.

[30] Tovar-Pescador J, Pozo-Vázquez D, Ruiz-Arias J, Batlles J, López G, Bosch J. On the use of DEM to estimate the solar radiation in complex topography areas. Meteorol App 2006; 279: 287-4.

[31] Batlles J, Bosch J, Tovar-Pescador J, Martinez-Durba N, Ortega R, Miralles I. Determination of atmospheric parameters to estimate global radiation in areas of complex topography: generation of global irradiation map. ECM 2008; 336: 345-6.

[32] Santamouris M, Tselepidaki I, Dris N. Evaluation of models for predicting solar radiation on tilted surfaces for the Mediterranean region. Sol Wind Technol 1991; 585: 589-2.

[33] Muneer T, Perez A. Slope irradiance and illuminance models: evaluation against Japanese data. Lighting Res Technol 1997; 83: 89-2. http://dx.doi.org/10.1177/14771535970290020201

[34] Isaaks E, Srivastava R. An Introduction to Applied Geostatistics. Oxford University: New York 1989; p. 561. 